\title{
Templated Grain Growth for High-Performance Lead-Free Piezoceramics
}

\author{
Seonhwa Park ${ }^{1,2}$, Cheol-Woo Ahn ${ }^{1}$, Jung Woo Lee ${ }^{2}$, Yuho Min ${ }^{1 \dagger}$ \\ ${ }^{1}$ Department of Functional Ceramics, Ceramic Materials Division, Korea Institute of Materials Science (KIMS), \\ Changwon, Gyeongnam, Korea, 51508 \\ ${ }^{2}$ Department of Materials Science and Engineering, Pusan National University, Busan, Korea, 46241
}

\section{템플릿 기반 일방향 그레인 성장을 통한 고성능 무연 압전 세라믹 제조 연구 동향}

\author{
박선화 ${ }^{1,2}$, 안철우 ${ }^{1}$, 이정우 ${ }^{2}$, 민유호 $^{1 \dagger}$ \\ 1한국재료연구원 기능세라믹연구실 \\ 2부산대학교 재료공학과
}

(Received May 4 2021; Accepted May 24 2021)

\begin{abstract}
s
As a new class of novel technologies for fabrication of piezoceramics, the templated grain growth (TGG) has been gaining tremendous attention due to the ability to align ferroelectric domains and thus improve piezoelectric properties, which are similar with the ones of single crystal. Towards the realization of textured grains in a specific direction, two-dimensional template materials should be preferentially needed with some specific conditions such as small lattice mismatch, similar crystal structure and composition compared to those of matrix piezoelectric ceramic powders. This mini review presents recent progress on TGG to provide highperformance textured $(\mathrm{K}, \mathrm{Na}) \mathrm{NbO}_{3}$ ceramics as an ideal lead-free to lead-based piezoceramics with a focus on the fabrication fundamentals and underlying mechanism. Additionally, some parameters related to the fabrication of green body during a tape casting are surveyed. Finally, we provide an insight into challenges and future directions in the TGG-based piezoceramics.
\end{abstract}

Keywords: Template, Grain Growth, Texturing, Piezoelectrics, Pb-Free ceramics, (K,Na) $\mathrm{NbO}_{3}$

†Corresponding Author: yuhomin@kims.re.kr 


\section{1. 서론}

결정구조의 이방성으로 인해 구성원자들의 위치가 비대칭인 경우 (non-centrosymmetry), 결정체에 압 력이 주어지면 원자들의 상대적인 위치 편차로 분극 이 발생할 수 있다. 이와 같은 원리로 기계적인 압력으 로 인해 전기 신호가 나오는 현상을 정압전 효과라 부 르며, 이와 반대로 전기적 신호를 이용하여 기계적 변 위를 나타내는 현상을 역압전 효과라 한다. ${ }^{1)}$ 32종의 결 정학적 점군 (crystallographic point group)에서 21 종이 비중심대칭으로 분류되며, 이중 20종은 압전체 로 작용한다. ${ }^{2}$ 이러한 현상을 활용하여, 압전소재 및 소 자는 센서, 헬스케어 모니터링, 바이오 이미징, 에너 지 하베스팅, 액추에이터 등 여러 산업 분야에 널리 사 용되고 있다. ${ }^{3)}$ 일반적으로 강유전특성을 지니는 소재 는 우수한 압전특성을 나타내며, 외부에서 전기장을 가 하면 일정방향으로 전기 분극이 발생하게 된다. ${ }^{12)}$ 이 와 같은 강유전체에서는 전기장의 방향에 따라 분극의 방향을 바꿀 수 있으며, 또한 전기장하에서 비선형적 인 전기 변위 (electric displacement)를 나타내고 이 력곡선 (hysteresis loop)을 보이게 된다. 외부 전기장 이 없을 때, 강유전체 결정 내부에서 형성된 자발 분극 (spontaneous polarization)은 일반적으로 여러 방향을 가지게 되는데, 이 때, 같은 방향을 갖는 일정 집합 영역 을 도메인 (domain)이라 하며, 분극 방향의 경계를 나 타내는 경계면을 도메인벽 (domain wall)이라 한다. 압 전 재료에 강한 전기장을 가하여 도메인을 전계 방향으 로 정렬시킴으로써, 외부적인 기계적 자극이 주어질 경 우 압전 현상을 나타내게 되며, 일반적으로 압전재료의 특성을 평가하는 항목은 다음과 같이 매우 많은 파라미 터들이 있다. (전기기계결합계수 $(k)$, 기계적품질계수 $\left(Q_{m}\right)$, 압전변형계수 $(d)$, 전압출력계수 $(g)$, 압전응력계 수 $(e)$, 전압응력계수 $(h)$, 유전율 $(\varepsilon)$, 유전손실 $(\tan \delta)$, 밀도, curie 온도 $\left(T_{c}\right)$ 등) 일반적으로 정압전 효과를 이 용하는 소자의 경우 우수한 전압출력계수 $(g)$ 를, 역압전 효과를 이용하는 경우엔 높은 압전변형계수 $(d)$, 유전 율, 탄성계수 등을 필요로 한다. ${ }^{4)}$
현재까지 납 $(\mathrm{Pb})$ 이 포함된 소재인 $\mathrm{Pb}(\mathrm{Zr}, \mathrm{Ti}) \mathrm{O}_{3}$ (PZT) 기반 세라믹스가 우수한 압전특성으로 인해 주로 사용되고 있으나, 전세계적으로 환경오염에 대한 관심 이 높아지면서, $\mathrm{Pb}$ 가 포함되지 않은 $\mathrm{Pb}$-free 소재 개발 이 요구되고 있다. ${ }^{5,6)}$ 특히, 유럽연합 (EU)에서 시작된 환경규제 조약들은 환경오염 물질인 $\mathrm{Pb}$ 의 사용을 엄격 히 제한하고 있으며, 압전소재에서는 PZT를 대체할 수 있는 $\mathrm{Pb}$-free 소재가 개발될 경우, $\mathrm{PZT}$ 사용이 금지 될 것으로 예측되고 있다. ${ }^{5,6)}$ 현재 개발 중인 대표적인 무연 압전소재들은 $(\mathrm{K}, \mathrm{Na}) \mathrm{NbO}_{3}(\mathrm{KNN}),(\mathrm{Na}, \mathrm{Bi}) \mathrm{TiO}_{3}$ $(\mathrm{NBT}),(\mathrm{Ba}, \mathrm{Ca})(\mathrm{Zr}, \mathrm{Ti}) \mathrm{O}_{3}(\mathrm{BCZT})$ 등이 있고, 최근에는 고온 압전소재인 $\mathrm{BiFeO}_{3}$ 가 널리 주목을 받고있다. ${ }^{3,7)}$ 하 지만, 여전히 $\mathrm{Pb}$ 기반 압전소재 대비 특성 측면에서 한 계를 보이고 있다.

압전소재는 결정립계 (grain boundary) 가 존재하지 않는 단결정 소재와 다수의 결정립계가 존재하는 다결 정 세라믹 소재로 나눌 수 있다. 일반적으로 단결정 소 재가 다결정 세라믹 대비 우수한 압전특성을 보이나, 결 정성장 비용과 시간이 많이 소모되며, 깨지기 쉽고, 크 기 및 형상의 제약으로 인해 사용이 극히 제한적이다. 다만 실제 고품질 (high-fidelity)을 요하는 환자 모니 터링, 초음파 이미지 등과 같은 의료 산업에만 부분적으 로 활용되고 있다. ${ }^{4,8)}$ 반대로 다결정 세라믹 압전 소재의 경우 공정가격이 매우 저렴하며, 강도가 상대적으로 우 수하나, 압전 성능이 낮은 문제를 지니고 있다. 따라서 가격이 저렴한 다결정 세라믹 측면에서 현재까지도 압 전 특성을 향상하고자 여러 전략들이 제안되었으며, 그 중 주된 방식은 다양한 원소들을 matrix에 첨가하여 도 핑 혹은 치환을 통한 조성제어 형태로 진행되고 있다. ${ }^{9}$ 이를 통해 압전소재의 여러 상 (phase)이 공존하는 영역 을 제어함으로써 (i.e. morphotropic phase boundary (MPB), polymorphic phase transition (PPT)) 전기장 하에서 도메인의 회전이 용이하게 일어나게 하고, 또한 격자 뒤틀림과 도메인벽의 움직임을 제어하여 특성 향 상을 가져올 수 있었다. ${ }^{10)}$ 그럼에도 불구하고, 조성개발 위주의 압전특성 향상 방법은 한계에 다다르고 있으며, 상당부분 많은 시간과 노력이 필요하다. 따라서, 공정 


\section{특 집 ㅂㅁ 박선화, 안철우, 이정우, 민유호}

가격은 저렴하면서도 조성개발 외적으로 단결정 수준의 압전특성을 구현할 수 있는 breakthrough 기술 개발이 필요한 실정이다.

조성변화를 통한 압전특성 개발이외에도 화학적 조성 에 크게 좌우되지 않으면서, 압전특성을 획기적으로 향 상시킬 수 있는 방법 중 하나는 결정립 혹은 도메인 엔 지니어링 (grain/domain engineering)기술이라 할 수 있다. 이는 결정립을 일방향으로 정렬시켜 마치 단결정 과 유사한 도메인 구조를 지니게 하는 것으로, 기존 다 결정 압전 세라믹 소재 대비 압전특성이 상당히 증가하 는 것으로 보고되고 있다. ${ }^{11)}$ 본 논문에서는 대표적인 무 연 압전 세라믹 중 하나인 $(\mathrm{K}, \mathrm{Na}) \mathrm{NbO}_{3}$ 계열 $(\mathrm{KNN})$ 소재 의 구조, 제조 방법, 특성향상을 위한 조성 제어 기술에
관해 우선 살펴보고, 고성능 압전특성 구현 전략에 대해 간략히 소개하고자 한다. 두번째로 배향성장 메커니즘, 고배향성장을 위한 성형체 제조 시 주요 고려사항, 배향 성장 $\mathrm{KNN}$ 계열 압전세라믹스의 연구 동향에 대해 소개 하고자 한다. 마지막으로는 결정립 배향성장 및 무연 압 전 세라믹스의 해결과제 및 전망에 대해 논하고자 한다.

\section{2. 무연압전셰라믹 - $(\mathrm{K}, \mathrm{Na}) \mathrm{NbO}_{3}$ 계열}

무연압전 소재 중 KNN계열 소재는 우수한 압전특 성 $\left(d_{33}\right)$ 과 높은 curie 온도 $\left(T_{c}\right)$ 로 인해 주목받는 대표 적인 압전재료 중 하나이다. ${ }^{12)} \mathrm{KNN}$ 은 $\mathrm{KNbO}_{3}(\mathrm{KN})$, $\mathrm{NaNbO}_{3}(\mathrm{NN})$ 의 고용체 형태로 $\mathrm{K}$ 와 $\mathrm{Na}$ 의 상대적 (a)

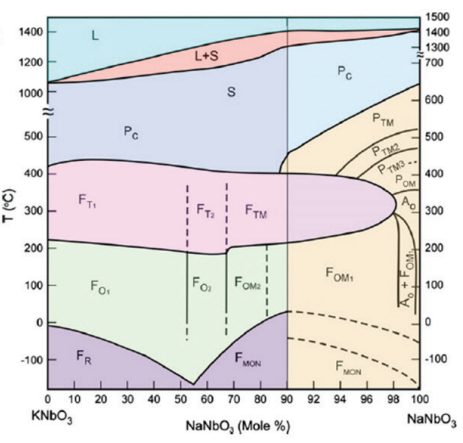

(c) $\mathrm{Nb}_{2} \mathrm{O}_{5}$ (Orthorhombic) (b)

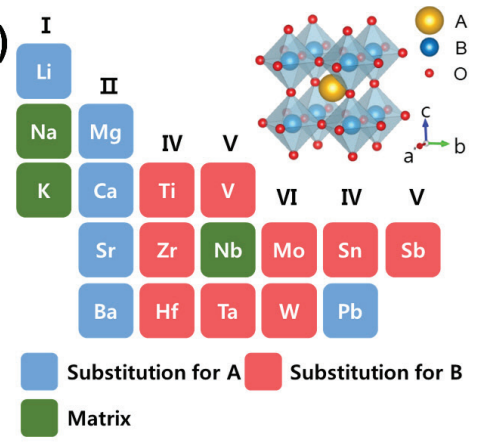

KNN (Orthorhombic)

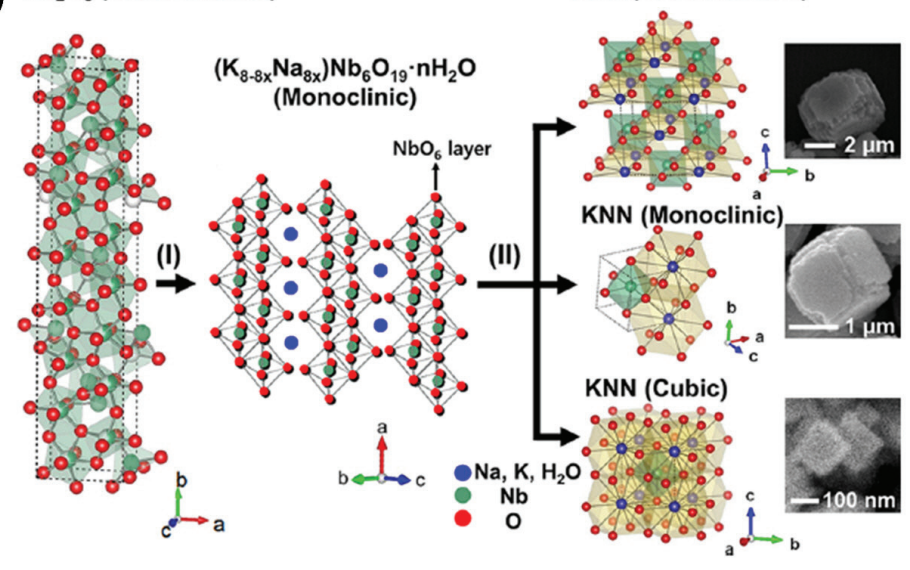

Fig. 1. Phase diagram of $\mathrm{KNbO}_{3}-\mathrm{NaNbO}_{3}$. Adopted from Li et al. J. Am. Ceram. Soc. 2013;96;3677-3696, with permission of WILEY. [14] (b) Diverse substitutional elements for $A$ and $B$ sites in $\mathrm{KNN}$-based perovskite materials $\left(\mathrm{ABO}_{3}\right)$. (c) Structural evolution of hydrothermally synthesized $(\mathrm{K}, \mathrm{Na}) \mathrm{NbO}_{3}$ particles with three different phases. Adopted from Park et al. Inorg. Chem. 2020;59;3042-3052, with permission of American Chemical Society. [26] 
인 원자비 변화가 가능하며, ${ }^{13)}$ 상태도에 의하면 온도 별로 다양한 상 (phase)을 지니게 되는데, $\mathrm{K}$ 와 $\mathrm{Na}$ 가 $1: 1$ 비율인 $\left(\mathrm{K}_{0.5} \mathrm{Na}_{0.5}\right) \mathrm{NbO}_{3}$ 조성에선, $-140{ }^{\circ} \mathrm{C}$ 이하 능 면체 (rhombohedral)상을, $-140{ }^{\circ} \mathrm{C} \sim 220{ }^{\circ} \mathrm{C}$ 에선 사 방정계 (orthorhombic), $220{ }^{\circ} \mathrm{C} \sim 420{ }^{\circ} \mathrm{C}$ 는 정방정계 (tetragonal), $420{ }^{\circ} \mathrm{C}$ 이상은 등축정계 (cubic)를 나타 낸다 (Fig. 1 (a)). ${ }^{14)} \mathrm{KNN}$ 소재는 페로브스카이트 구조 $\left(\mathrm{ABO}_{3}\right)$ 를 지니며, 이온크기가 비교적 큰 $\mathrm{K}$ 와 $\mathrm{Na}$ 양이 온이 A-site를, 비교적 작은 양이온인 $\mathrm{Nb}$ 가 $\mathrm{B}$-site를 차지하며, 기본 구조는 $\mathrm{NbO}_{6}$ 팔면체로 이들 팔면체의 코너를 연결하면서 페로브스카이트 결정 구조의 프레임 을 형성하게 된다. ${ }^{15)}$

압전특성 향상 전략 측면에서 살펴보면, 대부분의 연 구가 여러가지 원소를 $\mathrm{A}$ 및 $\mathrm{B}$-site에 일부 치환 혹은 도핑을 통해 결정상을 제어하는 방식으로 이루어져 왔 다. 이는 $\mathrm{Pb}$ 를 포함하는 납계 혹은 무연계 상관없이 공 통적으로 적용한 방식인데, phase boundary 제어를 통 해 압전소재의 전기적 특성을 향상시키는 결과를 가져 왔다. ${ }^{16,17)}$ 이는 여러 상이 공존 시, 혹은 하나의 상에서 다른 상으로 변화되려는 시점에서 압전성이 극대화되 는 현상을 이용하는 것으로, 폴링을 위해 전기장을 가해 줄 경우, 여러상에서 기인한 다양한 열역학적 도메인 배 열 상태들로 인해 강유전성 분극이 전기장 방향으로 쉽 게 정렬되는 것과 깊은 연관성을 가진다. ${ }^{18)} \mathrm{PZT}$ 와 달 리 KNN계 소재는 phase boundary 제어를 위해선 조 성뿐만 아니라 온도 역시 고려해야 하는데, 이는 앞의 상태도에서도 살펴보았듯이, 온도에 의해 상전이가 여 러 차례 일어나기 때문이다. 즉, polymorphic phase transition (PPT)으로 설명되는 것으로, 대표적인 상 전이는 3 가지 타입이 존재한다. ( $\mathrm{T}_{\mathrm{R}-\mathrm{O}}$ : rhombohedral to orthorhombic 전이 온도; $\mathrm{T}_{\mathrm{O}-\mathrm{T}}$ : orthorhombic to tetragonal 전이 온도; $\mathrm{T}_{\mathrm{R}-\mathrm{T}}$ : rhombohedral to tetragonal 전이 온도 ${ }^{19)}$ 결국, $\mathrm{MPB}$ 든 $\mathrm{PPT}$ 든 중요한 점은 이러한 phase boundary에서 다른 대칭상들이 존 재할 때, 분극이 쉽게 회전할 수 있고 소재의 유전성, 압 전성이 향상된다는 점이다. 일반적으로 상전이 온도가 상온부근으로 이동할 경우 압전특성이 보다 향상되므
로, $\mathrm{KNN}$ 계 소재에 첨가하는 원소는 상전이 온도를 이 동시킬 수 있는 능력을 지니는 것이 바람직하다. ${ }^{20)}$ 대표 적인 $\mathrm{A}$-site 치환 원소는 $\mathrm{Li}^{+}, \mathrm{Ag}^{+}$로 특히 $\mathrm{Li}$ 이온의 경 우 $\mathrm{T}_{\mathrm{c}}$ 를 높이고, $\mathrm{T}_{\mathrm{O}-\mathrm{T}}$ 를 상온부근까지 낮추어 $d_{33}$ 를 증가 시키는 것으로 알려져 있다. ${ }^{21,22)}$ 뿐만 아니라, 소결온도 를 낮추어서 고밀도 $\mathrm{KNN}$ 세라믹을 얻는데 유리한 첨가 제로 여겨진다. $\mathrm{B}$ - site 치환원소인 $\mathrm{Sb}^{5+}$ 와 $\mathrm{Ta}^{5+}$ 의 경우 $\mathrm{T}_{\mathrm{O}-\mathrm{T}}$ 를 낮추고, $\mathrm{T}_{\mathrm{R}-\mathrm{O}}$ 를 높이면서 압전특성 증가를 가져 오는 것으로 확인되었다 (Fig. 1(b)). ${ }^{23,24)}$

앞서 살펴본 첨가제를 통한 조성제어 연구는 대부분 고상반응 (solid-state reaction)을 통해서 이루어졌는 데, 이는 비교적 고온에서 높은 열에너지 공급이 가능 하기 때문에 도핑 혹은 치환 등이 비교적 수월하게 일어 날 수 있기 때문이다. 이와는 달리 액상에서 반응이 일 어나는 용액공정 역시 $\mathrm{KNN}$ 계 소재를 합성하는데 널 리 활용되고 있으며, 주로 적절한 열과 압력 하에서 수 열합성을 기반으로 이루어진다. ${ }^{25)}$ 기본적으로 결정구조 의 변화를 주기 위해서 가장 손쉬운 방법은 host물질과 이온반경이 다른 guest 원소를 일부 치환 혹은 도핑하 는 것으로, 격자의 뒤틀림을 유도하여 그 주변으로 상당 한 strain이 발생할 수 있고, 이에 따라 에너지적으로 보 다 안정한 상으로 변환될 수 있다. 고상반응과 달리 상 대적으로 저온에서 반응이 일어나는 용액공정의 경우, 치환 혹은 도핑에 필요한 에너지를 손쉽게 공급받지 못 할 수 있어서 이러한 반응이 고상반응 대비 수월하게 일 어나지 않는다. 그럼에도 불구하고 최근 연구 결과에 의 하면, 수열합성 시 도핑원소 없이 공정변수만 조절해서 상온에서 3 가지 다른 상 (monoclinic, orthorhombic, cubic)을 지니는 순수 $\mathrm{KNN}$ 입자를 선택적으로 합성하 는 결과가 발표되었다 (Fig. 1(c)). ${ }^{26)}$ 이는 layered 결정 구조를 지닌 중간체에서 $\mathrm{KNN}$ 상으로 변환될 때, 고에 너지 ultrasound를 활용하거나, 혹은 ethylene glycol 을 DI-water와 혼합용매로 사용할 경우, 결정구조의 symmetry가 변화되는 것을 활용한 결과이다. 그럼에도 불구하고, 고상반응 혹은 액상반응을 통한 $\mathrm{KNN}$ 계 소재 의 결정구조 제어 방식은 상당부분 연구가 진행되어 왔 고 특성향상 측면에서 한계에 도달하고 있으며, 이를 넘 

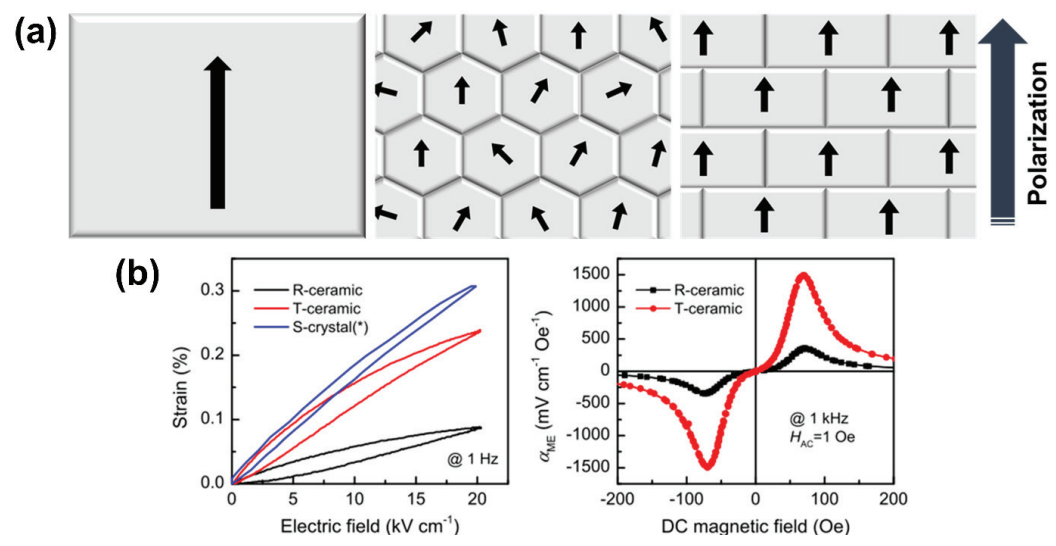

Fig. 2. (a) Schematic depictions of representative domain structures of ferroelectric single crystal, polycrystal ceramic, and textured ceramic. (b) A comparison of typical unipolar strain curves and magnetoelectric voltage coefficients for randomly oriented ceramic (R-ceramic), textured ceramic (T-ceramic), and single crystal (S-crystal). Adapted from Yan et al. Appl. Phys. Lett. 2013:102:042903, with permission of American Institute of Physics. [39]

어서서 보다 우수한 압전특성을 구현할 수 있는 새로운 breakthrough 기술 개발이 필요한 시점이다.

\section{3. 고성능 압전특성 구현 전략 (배향성장)}

앞에서 살펴보았듯이, 단결정 수준에 이르는 높은 압 전특성의 세라믹스를 제조하는 대표적인 방법은 세라믹 을 구성하는 각각의 그레인의 결정방위를 일방향으로 정렬시키는 것이다. 단결정, 다결정 세라믹, 그리고 배 향 세라믹의 가장 큰 차이는 폴링 전 후의 미세구조상의 대칭 (macroscopic symmetry)이라 할 수 있다. ${ }^{27)}$ 다결 정 세라믹의 경우, 각각의 그레인은 단결정처럼 취급될 수 있는데, 폴링 전에는 각각의 그레인의 방위가 무작위 해서 이들의 이방성의 방위가 상쇄되고 결국 실질적인 압전특성이 발현될 수 없다. 따라서, 폴링과정에서 전 기장을 가해주면 각각의 도메인들이 전기장 방향을 따 라서 정렬이 이루어져서 압전특성이 유도되나, 완벽하 게 한방향으로 정렬될 수 없기 때문에 단결정 대비 특성 이 떨어지며, 이외에도 실제 압전특성에 다양한 요소들 이 영향을 줄 수 있다. 예를 들면, 그레인 크기가 작을수 록 도메인의 크기가 작아지는 경향이 있으며, ${ }^{28)}$ 또한 그 레인 경계 (grain boundary)로 인해 도메인의 움직임이 방해받을 수 있다. ${ }^{29)}$ 결국 이러한 여러 요소들로 인해
다결정 세라믹의 평균 압전특성 저하를 가져온다. 이와 달리, 단결정의 경우 폴링 시에 가해진 전기장에 따라 에너지적으로 유리한 벡터들로 구성된 도메인 배열이 쉽게 형성되며, 이러한 도메인의 배열구조로 인해, 최소 한의 에너지를 요구하는 방위로 도메인이 쉽게 회전하 게 되어 높은 압전특성을 나타내게 된다. ${ }^{30)}$ 도메인이 가 질 수 있는 방위는 소재의 결정구조에 따라 달라지게 된 다. ${ }^{31)}$ 마지막으로 배향 세라믹의 경우, 폴링 후에 다결정 세라믹과 동일한 미세구조상의 대칭을 보이나, ${ }^{27)}$ 그레인 의 일방향 성장으로 인해 폴링 역시 일방향으로 정렬되 기 쉬우며, 따라서 다결정 세라믹에서 보여준 평균 압전 특성과 달리 단결정에 준하는 압전 특성을 구현할 수 있 다. ${ }^{30,32)}$ 하지만 다결정 세라믹과 마찬가지로 그레인 경 계에서의 도메인 움직임 방해 등으로 인해 단결정 보다 는 상대적으로 낮은 특성을 보여준다.

단결정을 성장시키는 대표적인 방식은 Bridgman, Czochralski, 및 top seeding solution crystal growth 등이 있으나, 고비용, 장시간, 조성의 불균일성, 후가 공의 어려움 등으로 인해 고가인 단점이 있어서 사용처 가 제한되는 문제가 있다. ${ }^{3)}$ 이와 달리 배향 다결정 세 라믹을 제조할 수 있는 공정으로는 압출 (extrusion), ${ }^{33)}$ Hot working, ${ }^{34)}$ Magnetic field 법 ${ }^{35,36)}$ 및 tapecasting $^{37,38)}$ 등이 대표적이며, 이 중 양산화에 가장 적 
합한 기술은 2 차원 형상의 template을 활용한 tapecasting 공정이라 할 수 있다. 실 예로, $\mathrm{BT}\left(\mathrm{BaTiO}_{3}\right)$ template을 사용해 tape-casting으로 $\mathrm{Pb}$ 계 다결정을 배향하였을 때, 배향 세라믹이 무배향 다결정보다 높은 변형률 특성을 나타내었다. 또한 단결정 $\mathrm{PZT}$ 의 압전특 성 $\left(d_{33}=1530 \mathrm{pC} / \mathrm{N}\right)$ 에 준할 정도의 고압전성 $\left(d_{33}=1100\right.$ $\mathrm{pC} / \mathrm{N})$ 을 보였으며, 뿐만 아니라 자기장을 가했을 경우 무배향 랜덤 다결정 세라믹 대비 배향 세라믹이 더 높은 분극률을 내는 것을 확인 할 수 있다 (Fig. 2(b)). ${ }^{39)}$

\section{1 배향성장 세라믹 제조 방법 및 메커니즘}

배향 세라믹 제조 메커니즘은 Templated Grain Growth (TGG)로 설명될 수 있다. Fig. 3. (a)는 TGG 를 위한 성형체 제조 공정 중 하나인 tape-casting에 대한 것으로, 이차원의 template과 matrix분말, 용매 및 유기 첨가제 (분산제, 가소제 등)등이 적절한 비율로 잘 혼합된 슬러리를 제조하는 것이 우선적으로 중요하 다. ${ }^{40)}$ 슬러리는 caster장비에서 blade를 통해 일정 높

(a)

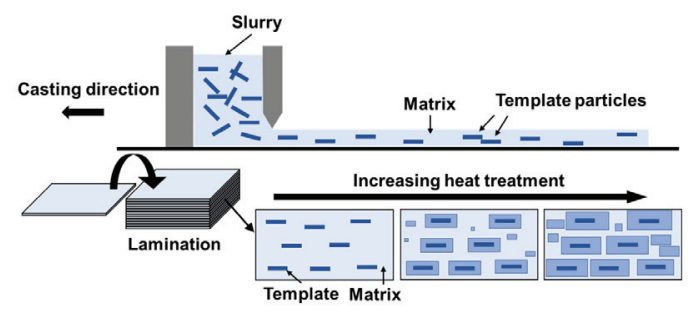

(b)

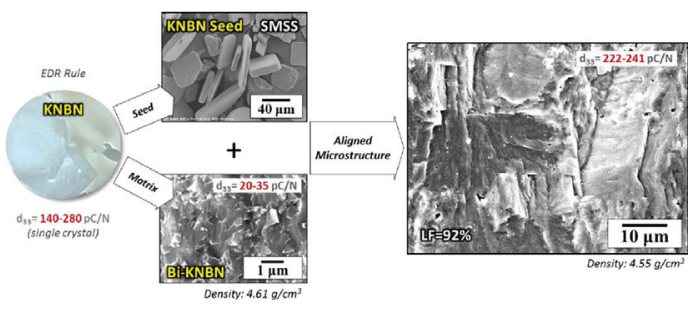

Fig. 3. (a) Schematic drawings of typical tape casting process for orientation of templates and resultant templated grain growth (TGG) with increasing heating temperature. (b) Scanning electron microscope (SEM) images showing Ba-doped KNN (KNBN) 2D seed, matrix, and TGG piezoceramics with enhanced $d_{33}$ similar to that of single crystal counterpart. Adapted from Park et al. J. Eur. Ceram. Soc. 2020;40;1232-1235, with permission of Elsevier Ltd. [43]
이의 tape형태로 casting 방향을 따라서 제조되며, 이 상적으로는 2차원 template들이 면상방향으로 잘 누워 있으며, tape 전반적으로 골고루 분산되어 있고, 그 사 이를 matrix 분말이 응집없이 분포하는 것이 가장 좋 다고 할 수 있다. ${ }^{41)}$ Tape 은 적절한 크기로 재단한 후 적층해서 성형체로 제조되며, 이러한 성형체는 burnout과정을 거쳐 유기물들을 완전히 제거하고 최종 소 결되어 배향 세라믹으로 제조된다. 열처리 과정에서 matrix 분말은 template 계면에서 핵 형성 및 반응을 통해 일방향 그레인 성장을 하게 된다. 이때 TGG의 구 동력 (driving force)은 template의 표면과 matrix 그 레인 사이의 계면에서 형성된 액상에 대한 용해도 차이 $(\triangle \mathrm{S})$ 로, 표면에너지로 인해 용해도가 큰 matrix가 계 면에서 용해되어 2차원 template의 결정방향을 따라 서 성장하게 된다. 이러한 성장 메커니즘은 GibbsThomson 식으로 설명할 수 있다. 소결 시 matrix의 용 해도는 $\mathrm{S}_{\mathrm{m}}$, template의 용해도는 $\mathrm{S}_{\mathrm{T}}$ 라 하고 matrix의 입자크기 $r_{\mathrm{m}}, \sigma_{\mathrm{m}}$ 은 matrix grain의 평균 표면 에너지, 밀도 $\rho$, 분자량 $\mathrm{M}$ 을 사용하여 아래의 식을 통해 matrix 와 template 사이의 용해도 차이를 확인할 수 있다. ${ }^{42)}$

$$
\mathrm{S}_{m}=S_{o} \exp \left(\frac{2 \sigma_{m} M}{\rho r_{m} R T}\right)
$$

또한 grain의 성장 속도도 알 수 있는데, 성장 속도 는 열처리 중 matrix와 template간의 용해도 차 $(\triangle S=$ $\mathrm{S}_{\mathrm{m}}-\mathrm{S}_{\mathrm{T}}$ )가 클수록, 확산계수 $\mathrm{D}$ 가 클수록 빠르며, 두 층 사이에서 생성되는 얇은 두께의 액상 층 $\delta$ 이 두꺼울수록 성장속도는 느리게 된다. ${ }^{42)}$

$$
\frac{\mathrm{dR}_{\mathrm{T}}}{\mathrm{dt}}=-\frac{\mathrm{J}}{\rho}=\frac{\mathrm{D} \Delta \mathrm{S}}{\rho \delta}
$$

최근 결과에 의하면, $\mathrm{KNN}$ 계열 배향세라믹을 제조하 였을 경우, 동일한 조성을 지닌 단결정 소재 에 준하는 고압전 특성을 얻을 수 있었으며, 이는 동일한 조성의 무배향 압전 세라믹 대비 압전특성이 약 $588 \%$ 증가됨을 보여준 결과였다(Fig. 3(b)). ${ }^{43)}$ 


\section{2 배향성장 주요 결정요인}

고배향성을 지닌 성형체를 제조하기 위해선 몇 가지 고려해야하는 사항들이 있다. 기본적으로 tape을 제조 하였을 때, 매트릭스용 분말과 2 차원 형상의template 들이 전반적으로 균일하게 분포하고 있어야 하며, 용 매의 휘발을 통한 건조가 적절하게 일어나서 균열이 발 생하지 않도록 해야 한다. 이를 위해서는 2 차원 형태의 template 제조, 균일 슬러리를 통한 적절한 tape 형 성, 건조 온도, tape의 적층, 번아웃 (burn-out), 그리 고 마지막 소결까지 다양한 변수를 고려해야 하며, 이 러한 각각의 주요 결정요인들에 대해 간단하게 살펴보 고자 한다.

\section{Matrix용 분말}

일반적으로 $\mathrm{TGG}$ 를 위해 사용되는 matrix용 분말은 슬러리로 제조되기 전에 최종 세라믹의 조성을 갖도록 우선적으로 열처리를 통한 하소과정을 거치며, 이러한 하소분말은 여러가지 유기 첨가제 (바인더, 분산제 등) 및 용매와 적절한 비로 혼합되어 슬러리로 제조된다. 분 말 입자의 크기는 최종 세라믹 미세구조 및 특성에 상당 한 영향을 미치게 되므로, 고밀도, 고배향 세라믹을 위 해선 적절한 입자 크기가 필요하다. ${ }^{44)}$ 입자 크기가 매우 작으면 높은 표면에너지로 인해 응집되려는 현상이 강 해지며, 이의 분산도를 높이기 위해 유기 첨가제 양을 증가시킬 경우, 최종 세라믹의 기공율이 높아지는 문제 를 가진다. 이와 반대로 입자크기가 매우 크면, 배향성 장이 어렵고 소결을 위해선 고온이 필요하기 때문에 고 밀도 세라믹을 제조하기엔 적합하지 않다. 뿐만 아니라, 이상적으로는 모든 분말의 입자들은 동일한 조성을 지 녀야 최종 소결 압전 세라믹에서도 균일한 조성 및 재현 성 있는 특성을 구현할 수 있다. ${ }^{45)}$

\section{슬러리 (slurry)}

슬러리는matrix분말과 template 뿐만 아니라 용매, 분산제, 바인더 등을 적절히 선택한 후 혼합하여 만들어 지며, 점도 등을 잘 제어하는 것이 중요하다. ${ }^{46)}$ 먼저 용 매의 경우 슬러리 제조 시 matrix 입자들을 고르게 분
산시키며, 유기 첨가제들이 용해가 잘 일어나도록 하는 역할을 한다. 또한 적절한 증발속도를 지닌 용매를 선 택하는 것이 중요한데, 만일 증발속도가 너무 빠를 경우 강한 모세관 현상에 의해 입자들이 뭉침 현상이 증가하 게 되고, 특정 입자들과 입자들 사이의 간격이 벌어지면 서 tape에 균열이 발생하게 된다. 이와 반대로, 용매의 증발속도가 매우 느릴 경우, 건조시간이 오래 걸릴 뿐만 아니라 액상 속에서 용질들의 재배열이 발생할 수 있어, tape 전체의 균일도 및 배향도가 떨어질 수 있다. ${ }^{47)}$ 대 표적인 용매인 톨루엔의 경우 용해능력은 좋으면서 적 절한 휘발 속도를 지니고 있지만, 인체 안전을 위해 사 용 시 주의가 필요하다. 최근엔 용매로 55-60 vol\%의 톨루엔과 45-40 vol\% 에탄올을 혼합하여 슬러리용 용 매로 많이 활용하고 있다. ${ }^{48,49)}$

분산제는 matrix용 분말 입자 표면을 안정화시켜 입 자 응집을 억제하고 슬러리의 점도를 낮추는 데 활용할 수 있다. 분산제 사용 시 상대적으로 많은 양의 고상분 말 (solid loading)을 사용할 수 있으며, 동시에 용매 양 을 줄일 수 있어서 tape의 건조시간 측면에서 유리할 수 있다. 하지만 분산제는 유기물이므로 소결 전 번아웃 단 계에서 완전하게 제거되어야 한다. ${ }^{50)}$

슬러리에 첨가되는 바인더의 역할은 tape에 강도, 유 연성, 내구성 등을 결정하고, 바인더의 종류에 따라 용 해도, 점도, 강도, liquid gelation temperature $\left(\mathrm{T}_{\mathrm{g}}\right)$ 번 아웃 온도 등이 다르므로 이에 대한 고려가 필요하다. 또한, 바인더는 입자와 입자사이를 연결해 젤 네트워크 (gel-network)를 형성하므로 tape 제조 시 매우 중요 한 역할을 한다. ${ }^{50)}$

\section{제단, 적층 및 소결 (cutting, laminating, and sintering)}

Tape casting을 통해 만들어진 tape은 일정한 크 기로 제단하고 (cutting), 적층 (laminating), 압축 (pressing)을 통해 적절한 두께를 지닌 성형체로 우선 제조된다. 만약 적층하는 tape의 수가 많아질 경우, 적 층 후에 압축 시 층사이에 균일한 온도와 압력 분포가 일어나지 않아 배열 분포가 불균일한 성형체가 만들어 질 수 있다. 따라서 적절한 두께를 지니도록 적층하고, 
압축시간과 온도를 최적화하여 전체적으로 균일한 조건 을 만들어 준다면 층 간의 박리를 최소화할 수 있다. ${ }^{51)}$ 적층하여 만든 성형체는 소결 전 번아웃 공정을 거치는 데, 이는 열처리를 통해 tape내의 유기 첨가제 및 잔류 물을 기화시키기 위함이다. 번아웃의 온도는 바인더가 기화되는 온도보다 높아야 하며, 승온속도를 천천히 함 으로써 시편내 균열을 방지하고 효과적으로 유기첨가제 를 제거할 수 있어야 한다. ${ }^{52,53)}$ 마지막으로 소결공정을 통해 matrix 입자들이 이차원형상의 template을 따라 일방향으로 배향성장하게 된다. 소결 시 적절한 온도 및 유지시간을 통해 template와 matrix입자 사이에서 안 정적으로 핵 생성 및 성장이 일어나도록 해야 한다. 이 를 통해 최종적으로 높은 밀도를 지닌 고배향 압전 세라 믹이 만들어질 수 있다. ${ }^{54}$

\section{2차원형상의 template}

현재까지 TGG에 사용되는 이차원 형상의 template 은 대부분 등화학미세치환법 (Topochemical molten slat synthesis (TMSS))으로 제조되어 왔다. ${ }^{55)}$ TMSS 는 무기염, 미리 제조된 (pre-made) 중간체template (a)

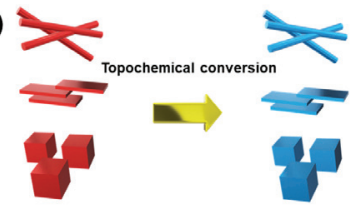

(c)

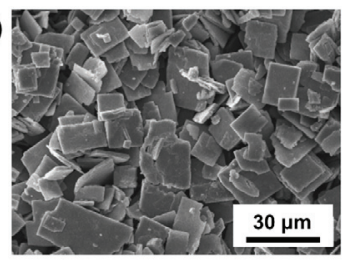

(b)

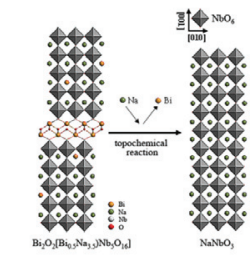

(d)

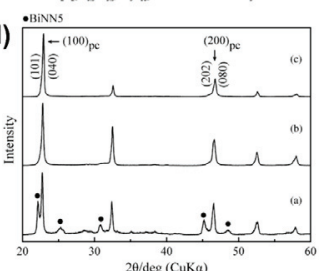

Fig. 4. (a) Schematic drawing showing a topochemical conversion process with retaining the initial shapes (1D, 2D, and 3D). (b) Typical example of topochemical conversion from bismuth layer-structured BiNN5 to $\mathrm{NaNbO}_{3}$ plates. (c) SEM image and (d) X-Ray Diffraction (XRD) pattern of resultant $\mathrm{NaNbO}_{3}$ templates. Reproduced form Yan et al. J. Am. Ceram. Soc 2007;90;2399-2403, with permission of WILEY. [58]
그리고 최종 반응물을 구성하는 원료분말 등을 혼합 한 후, 무기염의 용융온도 이상에서 반응물들간의 확 산, 치환, 제거 등을 통해 중간체 template의 형상은 유 지한 체 원하는 조성을 지닌 최종 생산물을 만들 수 있 는 용융염법의 대표적인 방식 중 하나이다. ${ }^{56)}$ Fig. 4(a) 에서 나타내듯이, TMSS는 1,2,3차원 형상의 중간체 template 모양은 유지한 체 조성만 변경하여 생산물을 제조할 수 있는 매우 획기적인 방법인데, 배향압전 세라 믹을 제조하기 위한 다양한 2차원 template $\left(\mathrm{BaTiO}_{3}\right.$, $\left.\mathrm{NaNbO}_{3}, 0.6\left(\mathrm{Na}_{0.5} \mathrm{Bi}_{0.5}\right) \mathrm{TiO}_{3}-0.4 \mathrm{PbTiO}_{3}\right)$ 역시 TMSS 방법으로 제조되고 있다. ${ }^{57)}$ 특히, 배향세라믹 제조용 2 차원 template 제조의 경우, 여러 단계를 거치게 되는 데, 먼저 2차원 형상을 지니는 중간체를 만드는 과정, 그리고 2차원 형상은 유지한 체 최종 template로 변 환하는 단계를 포함한다. ${ }^{55-57)} \mathrm{TMSS}$ 가 이러한 여러 단 계를 거쳐야하는 대표적인 이유는 압전소재들이 일반 적으로 이방성구조를 지니지만, 그래핀처럼 2 차원 형 상 구조 (layered structure)가 아니기 때문에, onestep으로 판상형태의 2차원 template으로 제조하기 는 열역학적으로 매우 힘들기 때문이다. 대표적인 예 로 2차원 $\mathrm{NaNbO}_{3}$ template 제조에 대한 설명이 Fig. 4(b)에 나타나 있다. ${ }^{58)}$ 아래의 식에서 나타난 것처럼 먼 저, 층상구조를 지닌 비스무스 화합물 $\left(\mathrm{B}_{\mathrm{i} 2.5} \mathrm{Na}_{3.5} \mathrm{Nb}_{5} \mathrm{O}_{18}\right.$ (BiNN5))을 우선적으로 제조한 후, TMSS반응을 통해 $\mathrm{Na}$ 와 $\mathrm{Bi}$ 이온 간 치환이 이루어 지면서 최종적으로 이 차원 형상의 $\mathrm{NaNbO}_{3}$ template가 만들어 진다. ${ }^{59)}$

$$
\begin{aligned}
& \text { 1.25 } \mathrm{Bi}_{2} \mathrm{O}_{3}+2.5 \mathrm{Nb}_{2} \mathrm{O}_{5}+1.75 \mathrm{Na}_{2} \mathrm{CO}_{3} \rightarrow \\
& \mathrm{Bi}_{2.5} \mathrm{Na}_{3.5} \mathrm{Nb}_{5} \mathrm{O}_{18}+1.75 \mathrm{CO}_{2} \uparrow \\
& \mathrm{Bi}_{2.5} \mathrm{Na}_{3.5} \mathrm{O}_{18}+1.5 \mathrm{Na}_{2} \mathrm{CO}_{3} \rightarrow \\
& 5 \mathrm{NaNbO}_{3}+1.2 \mathrm{Bi}_{2} \mathrm{O}_{3}+0.75 \mathrm{CO}_{2} \uparrow
\end{aligned}
$$

합성된 template은 Fig. 4(c), (d)처럼 SEM (scanning electron micrograph)을 통해 이차원의 형 상을 가지며, XRD (X-ray diffraction)를 통해 페로브 스카이트 구조로 확인되었다. 이와 같은 방법으로 동일 
Table 1. Piezoelectric properties of $\mathrm{KNN}$-based textured ceramics using $\mathrm{NaNbO}_{3}$ templates reported to data

\begin{tabular}{|c|c|c|c|c|c|c|c|c|}
\hline composition & $\begin{array}{l}\text { L.F. } \\
(\%)\end{array}$ & $\begin{array}{c}\mathrm{d}_{33} \\
(\mathrm{pC} / \mathrm{N})\end{array}$ & $\begin{array}{c}\mathrm{d}_{33} \\
(\mathrm{pm} / \mathrm{V})\end{array}$ & $\begin{array}{l}\mathrm{k}_{\mathrm{P}} \\
(\%)\end{array}$ & $\begin{array}{l}\mathrm{T}_{\mathrm{c}} \\
\left({ }^{\circ} \mathrm{C}\right)\end{array}$ & $\begin{array}{c}\mathrm{P}_{\mathrm{r}} \\
\left(\mu \mathrm{C} / \mathrm{cm}^{2}\right)\end{array}$ & $\begin{array}{c}\mathrm{E}_{\mathrm{c}} \\
(\mathrm{kV} / \mathrm{cm})\end{array}$ & Ref. \\
\hline $\begin{array}{l}0.92\left(\mathrm{Na}_{0.5} \mathrm{~K}_{0.5}\right) \mathrm{NbO}_{3}-0.06 \mathrm{BaZrO}_{3}- \\
0.02\left(\mathrm{Bi}_{0.5} \mathrm{Li}_{0.5}\right) \mathrm{TiO}_{3}\end{array}$ & 88 & 271 & - & - & 251 & 18.5 & 15 & [65] \\
\hline $0.94\left(\mathrm{~K}_{0.5} \mathrm{Na}_{0.5}\right) \mathrm{NbO}_{3}-0.06 \mathrm{LiSbO}_{3}$ & 87 & 192 & - & - & 348 & 25 & 15 & [63] \\
\hline $\begin{array}{l}0.99\left(\mathrm{~K}_{0.49} \mathrm{Na}_{0.49} \mathrm{Li}_{0.02}\right)\left(\mathrm{Nb}_{0.72} \mathrm{Ta}_{0.03} \mathrm{Ta}_{0.25}\right) \mathrm{O}_{3}- \\
0.01 \mathrm{CaZrO}_{3}\end{array}$ & 82.1 & 391 & 578 & 54.4 & 223 & 22 & 11 & [66] \\
\hline $0.95\left(\mathrm{Na}_{0.49} \mathrm{~K}_{0.49} \mathrm{Li}_{0.02}\right)\left(\mathrm{Nb}_{0.8} \mathrm{Ta}_{0.2}\right) \mathrm{O}_{3}-0.05 \mathrm{CaZrO}_{3}$ & 89.7 & 330 & 346 & 46.7 & 192 & 9.4 & 7.2 & [67] \\
\hline $\begin{array}{l}0.96\left(\mathrm{~K}_{0.5} \mathrm{Na}_{0.5}\right)\left(\mathrm{Nb}_{0.965} \mathrm{Sb}_{0.035}\right) \mathrm{O}_{3}-0.01 \mathrm{CaZrO}_{3}- \\
0.03\left(\mathrm{Bi}_{0.5} \mathrm{~K}_{0.5}\right) \mathrm{HfO}_{3}\end{array}$ & 98 & 700 & 980 & 76 & 242 & 37.6 & 8.4 & [68] \\
\hline $\begin{array}{l}0.96\left(\mathrm{~K}_{0.5} \mathrm{Na}_{0.5}\right)\left(\mathrm{Nb}_{0.965} \mathrm{Sb}_{0.035}\right) \mathrm{O}_{3}-0.01 \mathrm{CaZrO}_{3}- \\
0.03\left(\mathrm{Bi}_{0.5} \mathrm{~K}_{0.5}\right) \mathrm{HfO}_{3}\end{array}$ & 83 & 550 & - & 72 & 256 & 31 & 15 & [69] \\
\hline $\begin{array}{l}0.95\left(\mathrm{~K}_{0.5} \mathrm{Na}_{0.5}\right)\left(\mathrm{Nb}_{0.96} \mathrm{Sb}_{0.04}\right) \mathrm{O}_{3}-0.01 \mathrm{BaHfO}_{3}- \\
0.04\left(\mathrm{Bi}_{0.5} \mathrm{Na}_{0.5}\right) \mathrm{ZrO}_{3}\end{array}$ & 95.3 & 490 & 860 & 52 & 208 & 21.9 & 8 & [70] \\
\hline $\begin{array}{l}0.07\left(\mathrm{~K}_{0.5} \mathrm{Na}_{0.5}\right)_{0.98} \mathrm{Ag}_{0.02}\left(\mathrm{Nb}_{0.96} \mathrm{Sb}_{0.04}\right) \mathrm{O}_{3}- \\
0.03\left(\mathrm{Bi}_{0.5} \mathrm{Na}_{0.5}\right) \mathrm{ZrO}_{3}\end{array}$ & 97.6 & 550 & 560 & 66 & 250 & 20.7 & 10.2 & [71] \\
\hline
\end{tabular}

중간체 (BiNN5)를 사용하였을 때 $\mathrm{NaNbO}_{3}$ 뿐만 아니라 $\mathrm{KNbO}_{3}$ 를 제조할 수 있으며 또한, 층상구조 중간체인 $\mathrm{BaBi}_{4} \mathrm{Ti}_{4} \mathrm{O}_{15}$ 로 $\mathrm{BaTiO}_{3}$ template을 60) 중간체 $\mathrm{Sr}_{3} \mathrm{Ti}_{2} \mathrm{O}_{7}$ 에 서 $\mathrm{SrTiO}_{3}$ template을 제조할 수 있다. ${ }^{61)}$

\section{4. 고배향 KNN 계열 셰라믹}

2004년 Nature 저널에 고배향 KNN계열 세라믹의 우수한 압전 특성이 $\left(d_{33}=416 \mathrm{pC} / \mathrm{N}\right)$ 최초로 보고된 이 후, ${ }^{22}$ 현재까지 많은 연구자들이TGG공정을 활용하여 다양한 조성의 고배향 KNN 압전 세라믹을 제조해오고 있다. $\mathrm{Pb}$ 계열의 고배향 세라믹 제조 시 2차원 template 으로 $\mathrm{BaTiO}_{3},\left(\mathrm{Na}_{0.5} \mathrm{Bi}_{0.5}\right) \mathrm{TiO}_{3}-\mathrm{PbTiO}_{3}(\mathrm{NBT}-\mathrm{PT})$ 를 활용하는 것과 달리, $\mathrm{KNN}$ 계열의 경우 대부분 2 차원 $\mathrm{NaNbO}_{3}(\mathrm{NN})$ template을 활용하고 있다. 이는 앞서도 살펴보았듯이 KNN 계열 matrix분말과의 적합성이 가 장 우수하기 때문이다. ${ }^{63)} \mathrm{Li}$ 이 도핑된 $\mathrm{KNN}$ 세라믹 제조 시, NN template와 약 $850{ }^{\circ} \mathrm{C}$ 에서 배향 성장 결정립 의 핵생성이 일어나며, 온도 증가와 함께 가속화되어 상 호 반응이 활발하게 일어난다는 연구 결과가 보고 되었 다. ${ }^{64)}$ 이외에도, Table 1에 TGG를 활용하여 제조된 고 배향 $\mathrm{KNN}$ 세라믹에 대한 최근 결과 및 대표적은 압전 특성 값들을 요약하여 나타내었다. 63.65-71) 제조된 세라믹 의 배향 정도를 확인할 수 있는 대표적인 방법은 XRD
측정 값을 기준 값과 비교하는 것이다. 즉, 무배향 결정 립의 방위 대비 특정 방향으로 상대적으로 얼만큼 배향 이 이루어졌는지를 계산하는 것인데, 다음의 식과 같이 Lotgering factor (L.F.) (2) $^{72}$ 계산을 통해 확인할 수 있 다. 예를 들면, 모든 결정립들이 [001] 방향으로 배향되 어 있다면 $(P=1)$, [001] 방향에 대한 $\mathrm{LF}=100 \%$ 를 나타내 게 되며, 무배향 샘플처럼 특정 배향을 가지지 않을 경 우 $\left(P=P_{o}\right), \mathrm{LF}=0 \%$ 를 나타낸다.

$$
F_{00 l}=\frac{P-P_{o}}{1-P_{o}}, P=\frac{\sum I_{(00 l)}}{\sum I_{(h k l)}}, P_{o}=\frac{\sum I_{o(00 l)}}{\sum I_{o(h k l)}}
$$

2020 년 $\mathrm{Li}$ 연구팀은 $\mathrm{KNN}-\mathrm{BaHfO}_{3}-\left(\mathrm{Bi}_{0.5} \mathrm{Na}_{0.5}\right)$ $\mathrm{ZrO}_{3}$ 의 배향세라믹을 제조하여 우수한 압전특성 $d_{33}$ $=490 \mathrm{pC} / \mathrm{N}$ 과 높은 상변이 온도 $\mathrm{T}_{\mathrm{c}}=208^{\circ} \mathrm{C}$ 결 과를 보고 하였다. 이러한 결과는 조성제어를 통한 phase boundary (능면체 (Rhombohedral)와 정방 정계 (Tetragonal)이 공존하도록 설계) 와 $\mathrm{TGG}$ 를 활 용한 domain engineering을 통해 달성할 수 있었으 며, 무엇보다도 제조된 배향세라믹은 상온인 $25^{\circ} \mathrm{C}$ 에 서 $180^{\circ} \mathrm{C}$ 까지 결정구조 및 도메인 배열의 변화가 일 어나지 않아 고온 안정성을 보여주었다. ${ }^{70)}$ 같은 해인 2020년, Yang 연구팀이 높은 배향률 $($ L.F. $=97.6 \%)$ 을 지닌0.07( $\left(\mathrm{K}_{0.5} \mathrm{Na}_{0.5}\right)_{0.98} \mathrm{Ag}_{0.02}-\left(\mathrm{Nb}_{0.96} \mathrm{Sb}_{0.04}\right)_{3}-$ $0.03\left(\mathrm{Bi}_{0.5} \mathrm{Na}_{0.5}\right) \mathrm{ZrO}_{3}$ 압전 세라믹을 제조하였고, 

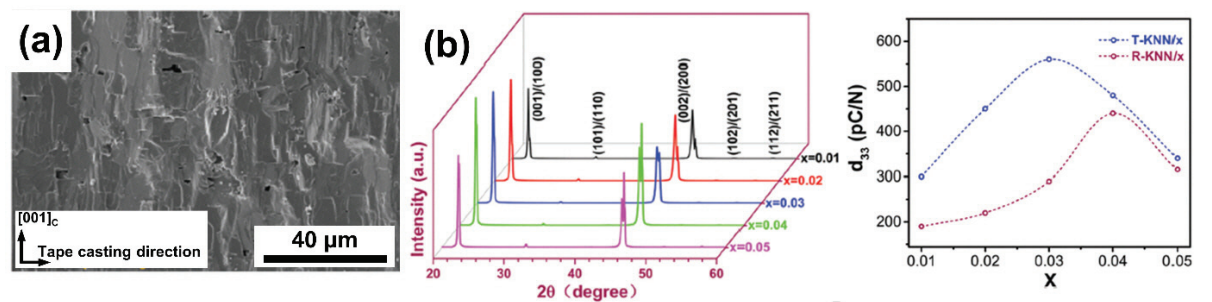

(c)

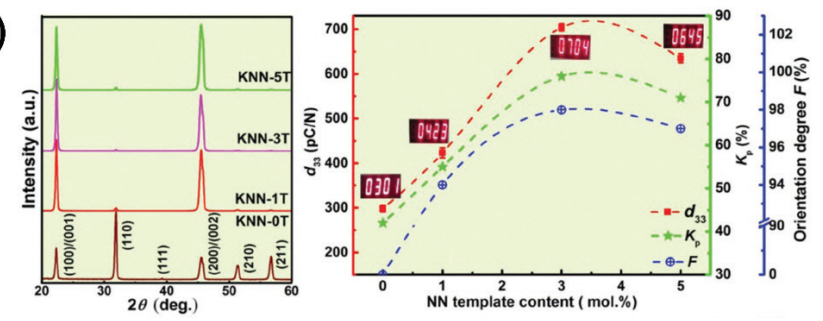

Fig. 5. (a) Cross-sectional SEM image of $\langle 001\rangle_{c}$-textured (1-x)KNANS-xBNZ (T-KNN/x=0.03). (b) XRD pattern and $d_{33}$ value of textured KNN ceramics depending on the fraction of $\mathrm{x}$. R-KNN indicates randomly oriented ceramics. Reproduced from Yang et al. J. Mater. Chem. C 2020;8;6149-6158, with permission of Royal Society of Chemistry. [71] (c) Variation in XRD pattern, orientation degree, $d_{33}$, and $k_{\mathrm{p}}$ value of $\langle 00 \mathrm{l}\rangle$-oriented $0.96 \mathrm{KNNS}-0.01 \mathrm{CZ}-0.03 \mathrm{BKH}$ ceramics prepared with different x mol\% $\mathrm{NaNbO}_{3}(\mathrm{NN})$ templates (KNN-xT). Reproduced from Li et al. Adv. Mater. 2018;30;1705171, with permission of WILEY. [68]

$\left(\mathrm{Bi}_{0.5} \mathrm{Na}_{0.5}\right) \mathrm{ZrO}_{3}$ 특정 함량 비에서 $\mathrm{T}_{\mathrm{R}-0}, \mathrm{~T}_{\mathrm{O}-\mathrm{T}}$ 가 상온부 근으로 이동되어 결국3가지 phase가 (rhombohedralorthorhombic-tetragonal $\mathrm{R}-\mathrm{O}-\mathrm{T}$ )공존하는 영역 을 발견하였다. 이러한 phase engineering과 더불어 domain engineering을 활용하여 우수한 압전특성을 구현하는데 성공하였다 $\left(d_{33}=550 \mathrm{pC} / \mathrm{N}\right)$ (Fig. 5 (a), (b)). ${ }^{71)}$ 특히, $\mathrm{R}-\mathrm{O}-\mathrm{T}$ 상전이 온도를 저온으로 낮춤으로 써, 상온에서부터 상변이 온도 $\left(T_{c}=250^{\circ} \mathrm{C}\right)$ 까지 온도 증 가에 따른 압전특성의 감소가 적은 배향 압전 세라믹을 제조할 수 있었다. 최근 연구결과에 의하면, 현재까지 $\mathrm{KNN}$ 계열 배향세라믹 중 가장 우수한 압전특성을 보이 는 소재는 $0.96\left(\mathrm{~K}_{0.5} \mathrm{Na}_{0.5}\right)\left(\mathrm{Nb}_{0.965} \mathrm{Sb}_{0.035}\right)-0.01 \mathrm{CaZrO}_{3}-$ $0.03\left(\mathrm{Bi}_{0.5} \mathrm{~K}_{0.5}\right) \mathrm{HfO}_{3}(96 \mathrm{KNNS}-1 \mathrm{CZ}-3 \mathrm{BKH})$ 로, $\mathrm{NN}$ template을 활용하여 2 step 소결 공정으로 제조되었 다 (Fig. 5(c) ${ }^{68)}$ 높은 배향성 및 phase boundary 제어 를 통해 $d_{33}=700 \mathrm{pC} / \mathrm{N}, d_{33} *=980 \mathrm{pm} / \mathrm{V}, k_{p}=0.76$ 등 $\mathrm{KNN}$ 계열 단결정에 준하는 매우 우수한 압전 특성 결과 를 보여주었다.

\section{5. 결론 및 전망}

본 논문에서는 저가의 방식으로 고품질 압전 특성 을 구현할 수 있는 대표적인 공정 방식 중 하나인 TGG 에 대해 살펴보았다. 이를 효과적으로 구현하기 위해, mechanism에 대한 기본적인 이해 및 성형체 제조용 tape casting시 주요 고려사항, 2차원 형상의 seed 제 조 및 고배향 $\mathrm{KNN}$ 다결정 압전 세라믹 연구 동향 등에 대해 확인하였다. TGG공정기술이 높은 압전 특성 구현 에 있어서 매우 획기적인 대안이 될 수 있는 것은 분명 하지만, 여전히 해결해야할 과제들이 많이 남아 있다. 일방향 결정립 정렬로 인해 압전 특성뿐만 아니라 소재 의 다양한 물성들 역시 이방성을 지니게 되며, 이러한 상황에서 반복적이고 안정적으로 소재가 널리 활용되 기 위해서는, 기계적, 열적, 광학적 이방성에 대한 이해 및 제어 방안 역시 필요할 것으로 보인다. 또한, $\mathrm{TGG}$ 로 활용되기 위해 현재까지 개발된 2차원 template 조 성 역시 매우 제한적이라는 문제를 가진다. 예를 들면, template과 matrix 분말의 조성이 크게 상이할 경우, 성분 원소들의 상호 확산현상으로 인해 배향되려는 것 
보다 우선적으로 상호 반응이 일어날 수 있으며, 이러 한 경우 고배향 세라믹을 얻기 어려울 수 있다. 즉, 다 양한 matrix분말 조성에 맞추어 여러가지 조성의 맞춤 형 2차원 template의 개발 역시 매우 필요한 시점이다. 조성이외에도 공정측면에서 2차원 template의 제조법 인 TMSS 역시 비용과 시간 측면에서 개선이 필요해 보 인다. TMSS는 기본적으로 2 단계 이상의 공정을 필요 로 하는데, 이를 one-step 용융염법을 통해 획기적으 로 단계를 줄일 수 있다면, TGG상용화 측면에서 매우 유리할 수 있다. 미세구조 측면에서 배향성장에 대한 mechanism을 설명하는 여러가지 이론들이 제안되어 왔으나, 고배향성을 위해 이를 보다 정밀하게 제어하기 위해선 보다 정확한 성장 및 구동 메커니즘에 대한 분석 이 필요하고, 이를 뒷받침하기 위한 다양한 in-situ 분 석법의 활용이 필요하다. 앞서 살펴보았듯이, 여러가지 해결되어야 할 이슈가 분명히 존재하지만, 그럼에도 불 구하고 TGG가 높은 고압전특성을 구현할 수 있는 새로 운 대안인 점은 분명하며, 조성개발과 동시에 보다 정밀 하게 결정립/도메인을 배향하고 제어하는 기술이 개발 된다면, 현재 사용중인 $\mathrm{Pb}$ 계열 압전소재 이상의 성능을 구현하면서, 친환경적인 압전 소재 및 소자 개발이 가능 할 것이다.

\section{Acknowledgement}

This research was supported by the Basic Science Research Program through the National Research Foundation (NRF) of Korea funded by the Ministry of Education (NRF-2019R1F1A1059646)

\section{REFERENCES}

1. H. Jaffe, "Piezoelectric Ceramics," J. Am. Ceram. Soc., 41 494-498 (1958).

2. K. M. Ok, E. O. Chi, and P. S. Halasyamani, "Bulk characterization methods for non-centrosymmetric materials: second-harmonic generation, piezoelectricity, pyroelectricity, and ferroelectricity," Chem. Soc. Rev., 35 710-717 (2006).

3. J. Koruza, H. Liu, M. Höfling, M.-H. Zhang, and P. Verber " $(\mathrm{K}, \mathrm{Na}) \mathrm{NbO}_{3}$-based piezoelectric single crystals: growth methods, properties, and applications," J. mater. Res., 35 990-1016 (2020).

4. Y. Zhang, and J.-F. Li "Review of chemical modification on potassium sodium niobite lead-free piezoelectrics," J. Mater. Chem. C, 7 4284-4303 (2019).

5. X. Gao, Z. Cheng, Z. chen, Y. Liu, X. Meng, X. Zhang, J. Wang, Q. Cuo, B. Li, H. Sun, Q. Gu, H. Hao, Q. Shen, J. Wu, X. Liao, S.P. Ringer, H. Liu, L. Zhang, W. Chen, F. Li, and S. Zhang, "The mechanism for the enhanced piezoelectricity in multi-elements doped (K,Na) $\mathrm{NbO}_{3}$ ceramicsm" Nat. Commun., 12881 (2021)

6. J. G. Wu, D. Q. Xiao, and J. G. Zhu, "Potassiumsodium niobate lead-free piezoelectric materials: past, present, and future of phase boundaries," Chem. Rev., 115 2559-2595 (2015).

7. X. Lv, X.-X. Zhang, and J. Wu, "Nano-domains in lead-free piezoceramics: a review," J. Mater. Chem. A, 8 10026-10073 (2020).

8. B. Liu, X. Liu, P. Li, F. Li, B. Shen, and J. Zhai, "Improving piezoelectric properties by controlling phase structure and crystal orientation," RSC $A d v$., 7 41788-41795 (2017).

9. J. E. Garcia, and F. Rubio-Marcos, "Polymorphic phase boundary in piezoelectric oxides," J. Appl. Phys., 127 131102 (2020).

10. M.-H. Zhang, H. C. Thong, Y. X. Lu, W. Sun, J.-F. $\mathrm{Li}$, and $\mathrm{K}$. Wang, " $(\mathrm{K}, \mathrm{Na}) \mathrm{NbO}_{3}$-based lead-free piezoelectric materials: an encounter with scanning probe microscopy," J. Kor. Ceram. Soc., 54 261-271 (2017).

11. K. Wang, and J.-F. Li, "Domain engineering of leadfree Li-modified $(\mathrm{K}, \mathrm{Na}) \mathrm{NbO}_{3}$ polycrystals with highly enhanced piezoelectricity," Adv. Funct. Mater., 20, 1924-1929 (2010).

12. H.-C. Thong, C. Zhao, Z. Zhou, C.-F. Wu, Y.-X. Liu, Z.-Z. Du, J.-F. Li, W. Gong, K. and K. Wang, "Technology transfer of lead-free $(\mathrm{K}, \mathrm{Na}) \mathrm{NbO}_{3}$-based piezoelectric ceramics," Mater. Today, 29 37-48 (2019). 
13. S. Zhang, H. J. Lee, C. Ma, and X. Tan, "Sintering effect on microstructure and properties of $(\mathrm{K}, \mathrm{Na})$ $\mathrm{NbO}_{3}$ ceramics," J. Am. Ceram. Soc., 94 3659-3665 (2011).

14. J.-F. Li, K. Wang, F.-Y. Zhu, L.-Q. Cheng, and F.-Z. Yao, “( $\mathrm{K}, \mathrm{Na}) \mathrm{NbO}_{3}$-based lead-free piezoceramics: fundamental aspects, processing technologies, and remaining challenges," J. Am. Ceram. Soc., 963677 3696 (2013).

15. J. Wang, and L. Luo, "The $\mathrm{NbO}_{6}$ octahedral distortion and phase structural transition of $\mathrm{Eu}^{3+}$-doped $\mathrm{K}_{0.5} \mathrm{Na}_{0.5} \mathrm{NbO}_{3}$-xLiNbO${ }_{3}$ ferroelectric ceramics," $J$. Am. Ceram. Soc., 101 400-407 (2018).

16. H. Zhao, Y. Hou, X. Yu, M. Zheng, and M. Zhu, "Ultra-broad temperature insensitive ceramics with large piezoelectricity by morphotropic phase boundary design," Acta Mater., 181 238-248 (2019).

17. M. H. Lee, D. J. Kim, J. S. Park, S. W. Kim, T. K. Song, M.-H. Kim, W.-J. Kim, D. Do, and I.-K. Jeong, "High-performance lead-free piezoceramics with high curie temperature," Adv. Mater., 27 6976-6982 (2015).

18. X. Lv, J. Zhu, D. Xiao, X.-X. Zhang, and J. Wu, "Emerging new phase boundary in potassium sodiumniobate based ceramics," Chem. Soc. Rev., $49671-$ 707 (2020).

19. T. Zheng, H. Wu, Y. Yuan, X. Lv, Q. Li, T. Men, C. Zhao, D. Xiao, J. Wu, K. Wang, J.-F. Li, Y. Gu, J. Zhu, and S. J. Pennycook, "The structural origin of enhanced piezoelectric performance and stability in lead free ceramics," Energy Environ. Sci., 10 528-537 (2017).

20. T. Zheng, J. Wu, D. Xiao, and J. Zhu, "Recent development in lead-free perovskite piezoelectric bulk materials," Prog. Mater. Sci., 98 552-624 (2018).

21. Y. Guo, K. Kakimoto, and H. Ohsato, "Phase transitional behavior and piezoelectric properties of $\left(\mathrm{Na}_{0.5} \mathrm{~K}_{0.5}\right) \mathrm{NbO}_{3}-\mathrm{LiNbO}_{3}$ ceramics," Appl. Phys. Lett., 85 4121-4123 (2004).

22. C. Lei, and Z.-G. Ye, "Lead-free piezoelectric ceramics derived from the $\mathrm{K}_{0.5} \mathrm{Na}_{0.5} \mathrm{NbO}_{3}-\mathrm{AgNbO}_{3}$ solid solution system," Appl. Phys. Lett., 93042901 (2008).

23. X. Wang, J. Wu, D. Xiao, J. Zhu, X. Cheng, T. Zheng, B. Zhang, X. Lou, and X. Wang, "Giant piezoelectricity in potassium-sodium niobite lead-free ceramics," J. Am. Chem. Soc., $1362905-2910$ (2014).
24. X. Wang, J. Wu, D. Xiao, X. Cheng, T. Zheng, B. Zhang, X. Lou, and J. Zhu, "Large $d_{33}$ in $(\mathrm{K}, \mathrm{Na})$ (Nb, Ta, $\mathrm{Sb}) \mathrm{O}_{3}-(\mathrm{Bi}, \mathrm{Na}, \mathrm{K}) \mathrm{ZrO}_{3}$ lead-free ceramics," $J$. Mater. Chem. A, 2 4122-4126 (2014).

25. R. I. Walton, "Perovskite oxides prepared by hydrothermal and solvothermal synthesis: a review of crystallization, chemistry, and compositions," Chem. Eur. J., 26 9041-9069 (2020).

26. S. Park, M. Peddigari, J. H. Kim, E. Kim, G.-T. Hwang, J.-W. Kim, C.-W. Ahn, J.-J. Choi, B.-D. Hahn, J.-H. Choi, W.-H. Yoon, D.-S. Park, K.-I. Park, C. K. Jeong, J. W. Lee, and Y. Min, "Selective phase control of dopant-free potassium sodium niobite perovskites in solution," Inorg. Chem., 59 3042-3052 (2020).

27. A. D. Moriana, and S. Zhang, "Lead-free textured piezoceramics using tape casting: a review," $J$. Materiomics, 4 277-303 (2018).

28. W. Cao, and C. A. Randall, "Grain size and domain size relations in bulk ceramic ferroelectric materials," J. Phys. Chem. Solids, 57 1499-1505 (1996).

29. J. Schultheiß, S. Checsia, H. Uršič, T. Frömling, J. E. Daniels, B. Malič, T. Rojac, and J. Koruza, "Domain wall-grain boundary interaction in polycrystalline $\mathrm{Pb}\left(\mathrm{Zr}_{0.7} \mathrm{Ti}_{0.3}\right) \mathrm{O}_{3}$ piezoceramics," J. Eur. Ceram. Soc., 40 3965-3973 (2020).

30. S. Zhang, and F. Li, "High performance ferroelectric relaxor- $\mathrm{PbTiO}_{3}$ single crystals: status and perspective," J. Appl. Phys., 111031301 (2012).

31. M. Davis, M. Budimir, D. Damjanovic, and N. Setter, "Rotator and extender ferroelectrics: importance of the shear coefficient to the piezoelectric properties of domain-engineered crystals and ceramics," J. Appl. Phys., 101054112 (2007).

32. A. J. Bell, "Phenomenologically derived electric field-temperature phase diagrams and piezoelectric coefficients for single crystal barium titanate under fields along different axes," J. Appl. Phys., $893907-$ 3914 (2001).

33. L. Liu, "Progress on the fabrication of lead-free textured piezoelectric ceramics: perspectives over 25 years," J. Mater. Sci., $264425-4437$ (2015).

34. Y. Yoshizawh, K. Hirao, and S. Kanzaki, "Mechanical properties of textured alumina made by hightemperature deformation," J. Am. Ceram. Soc., 87 2147-2149 (2004). 
35. Y. Sakka, T. S. Suzuki, and T. Uchikoshi, "Fabrication and some properties of textured alumina-related compounds by colloidal processing in high-magnetic field and sintering," J. Eur. Ceram. Soc., 28 935-942 (2008).

36. Z. Gao, T. S. Suzuki, S. Grasso, Y. Sakka, and M. J. Reece, "Highly anisotropic single crystal-like $\mathrm{La}_{2} \mathrm{Ti}_{2} \mathrm{O}_{7}$ ceramic produced by combined magnetic field alignment and templated grain growth," J. Eur. Ceram. Soc., 35 1771-1776 (2015).

37. H. Leng, Y. Yan, H. Liu, M. Fanton, R. J. Meyer, and S. Priya, "Design and development of highpower piezoelectric ceramics through integration of crystallographic texturing and acceptor-doping," Acta. Mater, 206116610 (2021).

38. H. Du, Y. Chang, C. Li, Q. Hu, J. Pang, Y. Sun, F. Weyland, N. Novak, and L. Jin, "Ultrahigh room temperature electrocaloric response in lead-free bulk ceramics via tape casting," J. Mater. Chem. C, 7 68606866 (2019).

39. Y. Yan, K.-H. Cho, D. Maurya, A. Kumar, S. Kalinlin, A. Khachaturyan, and S. Priya, "Giant energy density in [001]-textured $\mathrm{Pb}\left(\mathrm{Mg}_{1 / 3} \mathrm{Nb}_{2 / 3}\right) \mathrm{O}_{3}-\mathrm{PbZrO}_{3}-\mathrm{PbTiO}_{3}$ piezoelectric ceramics," Appl. Phys. Lett., 102042903 (2013).

40. H. Amorin, L. Santacruz, J. Holc, M. P. Thi, M. Kosec, R. Moreno, and M. Alqueró, "Tape-casting performance of ethanol slurries for the processing of textured PMN-PT ceramics from nanocrystalline powder," J. Am. Ceram. Soc., 92 996-1001 (2009).

41. H. J. Kims, M. J. M. Krane, K. P. Trumble, and K. J. Bowman, "Analytical fluid flow models for tape casting," J. Am. Ceram. Soc., 89 2769-2775 (2006).

42. G. L. Messing, S. Trolier-Mckinstry, E. M. Sabolsky, C. Duran, S. Kwon, B. Brahmaroutu, P. Park, H. Yilmaz, P. W. Rehrig, K. B. Eitel, E. Suvaci, M. Seabaugh, and K. S. Oh, "Templated grain growth of textured piezoelectric ceramics," Crit. Rev. Solid state., 29 45-96 (2004).

43. S. Park, A. Rahman, Y. Min, G.-T. Hwang, J.-J. Choi, B.-D. Hahn, K.-H. Cho, J. W. Lee, S. Nahm, and C.-W. Ahn, "An easy approach to obtain textured microstructure and transparent seed crystal prepared by simple molten salt synthesis in modified potassium sodium niobite," J. Eur. Ceram. Soc., 40 1232-1232 (2020).
44. E. Suvaci, K.-S. Oh, and G. L. Messing, "Kinetics of template growth in alumina during the process of templated grain growth (TGG)," Acta Mater., 49 2075-2081 (2001).

45. H. A. Cha, and J.-H. Jeon, "Texturing behaviours of $\left(\mathrm{K}_{0.47} \mathrm{Na}_{0.51} \mathrm{Li}_{0.02}\right)\left(\mathrm{Nb}_{0.8} \mathrm{Ta}_{0.2}\right) \mathrm{O}_{3}$ piezoelectric ceramics produced using $\mathrm{NaNb}_{1-\mathrm{x}} \mathrm{Ta}_{\mathrm{x}} \mathrm{O}_{3}$ templates," J. Eur. Ceram. Soc., 38 1442-1449 (2018).

46. J. W. Bender, and N. J. Wagner, “Optical measurement of the contributions of colloidal forces to the rheology of concentrated suspensions," J. Colloid Interface Sci., 172 171-184 (1995).

47. L. A. Salam, R. D. Matthews, and H. Robertson, "Optimisation of thermoelectric green tape characteristics made by the tape casting method," Mater. Chem. Phys., 62 263-272 (2000).

48. K. Fuse, and T. Kimura, "Effect of particle sizes of starting materials on microstructure development in textured $\mathrm{Bi}_{0.5}\left(\mathrm{Na}_{0.5} \mathrm{~K}_{0.5}\right)_{0.5} \mathrm{TiO}_{3}$," J. Am. Ceram. Soc., 89 1957-1964 (2006).

49. T. Sato, Y. Yoshida, and T. Kimura, "Preparation of $<110>$-textured $\mathrm{BaTiO}_{3}$ ceramics by the reactivetemplated grain growth method using needlelike $\mathrm{TiO}_{2}$ particles," J. Am. Ceram. Soc., 90 3005-3008 (2007).

50. Y. El Hafiane, A. Smith, T. Chartier, Y. Abouliatim, L. Nibou, and J.-P. Bonnet, "Role of dispersant and humidity on the setting of millimetric films of aluminous cement prepared by tape casting," J. Eur. Ceram. Soc., 32 2103-2111 (2012).

51. T. Claaßen, and N. Claussen, "Processing of ceramicmatrix/platelet composites by tape casting and lamination,” J. Eur. Ceram. Soc., 10 263-271 (1992).

52. A. Nair, and R. L. White, "Effects of inorganic oxides on polymer binder burnout. I. Poly(vinyl butyral)," $J$. Appl. Polym. Sci., 60 1901-1909 (1996).

53. A. Nair, and R. L. White, "Effects of inorganic oxides on polymer binder burnout. II. Poly(butyl methacrylate)," J. Appl. Polym. Sci., 60 1911-1920 (1996).

54. R. L. Walton, M. D. Vaudin, A.-K. Hofer, E. R. Kupp, R. J. Meyer, and G. L. Messing, "Tailoring particle alignment and grain orientation during tape casting and templated grain growth," J. Am. Ceram. Soc., 102 2405-2414 (2019).

55. L. Li, J. Deng, J. Chen, and X. Xing, “Topochemical molten salt synthesis for functional perovskite 
compounds," Chem. Sci., 7 855-865 (2016).

56. R. E. Schaak, and T. E. Mallouk, "Perovskites by design: a toolbox of solid-state reactions," Chem. Mater., 14 1455-1471 (2002).

57. P. Xue, H. Wu, Y. Lu, and X. Zhu, "Recent progress in molten salt synthesis of low-dimensional perovskite oxide nanostructures, structural characterization, properties, and functional applications: a review," $J$. Mater. Sci. Technol., 34 914-930 (2018).

58. Y. Yan, D. Liu, W. Zhao, H. Zhou, and H. Fang, "Topochemical synthesis of a high-aspect-ratio platelet $\mathrm{NaNbO}_{3}$ template," J. am. Ceram. Soc., 90 2399-2403 (2007).

59. Y. Kong, J. Hao, and D. Xu "Synthesis of anisotropic $\mathrm{NaNbO}_{3}$ seed crystals and fabrication of textured $\left(\mathrm{K}_{0.5} \mathrm{Na}_{0.5}\right) \mathrm{NbO}_{3}$-based ceramics," J. Mater. Sci: Mater. Electron, 27 11256-11261 (2016).

60. D. Liu, Y. Yan, and H. Zhou "Synthesis of micronscale platelet $\mathrm{BiTiO}_{3}$," J. Am. Ceram. Soc., $901323-$ 1326 (2007).

61. M. E. Ebrahimi, M. Alahverdi, and A. Safari, "Synthesis of high aspect ratio platelet $\mathrm{SrTiO}_{3}$, , J. Am. Ceram. Soc., 88 2129-2132 (2005).

62. Y. Saito, H. Takao, T. Tani, T. Nonoyama, K. Takatori, T. Homma, T. Nagaya, and M. Nakamura, "Lead-free piezoceramics," Nature, 432 84-87 (2004).

63. L. Li, W. Bai, Y. Zhang, B. Shen, J. Zhai and H. Chen, "Effect of different templates on electrical properties of textured KNN-based ceramics," Ferroelectrics, 490 85-93 (2016).

64. G. Tutuncu, Y. Chang, S. Poterala, G. L. Messing, and J. L. Jones, "In Situ observations of templated grain growth in $\left(\mathrm{Na}_{0.5} \mathrm{~K}_{0.5}\right)_{0.98} \mathrm{Li}_{0.02} \mathrm{NbO}_{3}$ piezoceramics: texture development and template-matrix interactions," J. Am. Ceram. Soc., 95 2653-2659 (2012).

65. L. Li, W. Bai, Y. Zhang, B. Shen, and J. Zhai, "The preparation and piezoelectric property of textured
KNN-based ceramics with plate-like $\mathrm{NaNbO}_{3}$ powders as template," J. Alloys Compd., 622 137-142 (2015).

66. B. Liu, P. Li, B. Shen, J. Zhai, Y. Zhang, F. Li, and X. Liu, "Simultaneously enhanced piezoelectric response and piezoelectric voltage coefficient in textured KNNbased ceramics," J. Am. Ceram. Soc., 101 265-273 (2018).

67. H. Zhang, Y. Zhu, P. Fan, M. A. Marwat, W. Ma, K. Liu, H. Liu, B. Xie, K. Wang, and J. Koruza, "Temperature-insensitive electric-field-induced strain and enhanced piezoelectric properties of $<001>$ textured (K,Na) $\mathrm{NbO}_{3}$-based lead-free piezoceramics," Acta Mater., 156 389-398 (2018).

68. P. Li, J. Zhai, B. Shen, S. Zhang, X. Li, F. Zhu, and X. Zhang, "Ultrahigh piezoelectric properties in textured (K,Na) $\mathrm{NbO}_{3}$-based lead-free ceramics," Adv. Mater., 301705171 (2018).

69. P. Li, Y. Huan, W. Yang, F. Zhu, X. Li, X. Zhang, B. Shen, and J. Zhai, "High-performance potassiumsodium niobite lead-free piezoelectric ceramics based on polymorphic phase boundary and crystallographic texture," Acta Mater., 165 485-495 (2019).

70. P. Li, Z. Fu, F. Wang, Y. Huan, Z. Zhou, J. Zhai, B. Shen, and $\mathrm{S}$. Zhang, "High piezoelectricity and stable output in BaHfO3 and $\left(\mathrm{Bi}_{0.5} \mathrm{Na}_{0.5}\right) \mathrm{ZrO}_{3}$ modified $\left(\mathrm{K}_{0.5} \mathrm{Na}_{0.5}\right)\left(\mathrm{Nb}_{0.96} \mathrm{Sb}_{0.04}\right) \mathrm{O}_{3}$ textured ceramics," Acta Mater., 199 542-550 (2020).

71. W. Yang, Y. Wang, P. Li, S. Wu, F. Wang, B. Shen, and J. Zhai, "Improving electromechanical properties in KNANS-BNZ ceramics by the synergy between phase structure modification and grain orientation," $J$. Mater. Chem. C, 8 6149-6158 (2020).

72. Y. Chang, J. Wu, Z. Liu, E. Sun, L. Liu, Q. Kou, F. Li, B. Yang, and W. Cao, "Grain-oriented ferroelectric ceramics with single-crystal-like piezoelectric properties and low texture temperature," ACS Appl. Mater. Interfaces, 12 38415-38424 (2020). 


\section{특 집 ㅁㅃ 박선화, 안철우, 이정우, 민유호}

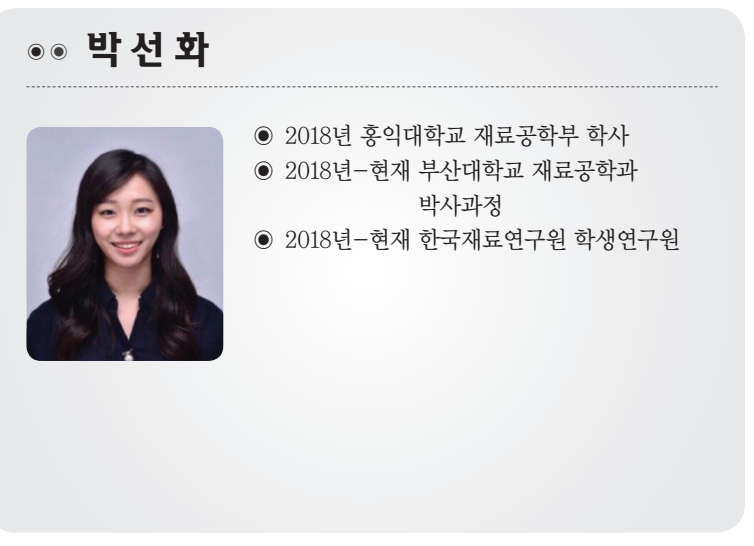

\section{․이정 우}

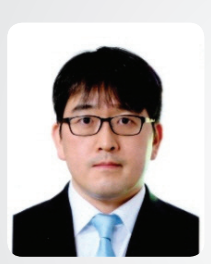

( 2004년 고려대학교 재료공학부 학사

- 2011년 한국과학기술원 신소재공학과 박사

- 2013년-2017년 University of Illinois at Urbana-Champaign 박사 후 연구원

( 2017년-2021년 부산대학교 재료공학부 조교수

( 2021년-현재 부산대학교 재료공학부 부교수

\section{ㅇ안 철 우}

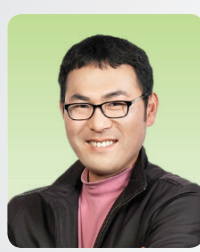

( 2006년 고려대학교 재료공학 박사

- 2007년-2008년 서울대학교 박사 후 연구원

- 2008년-2009년 Virginia Tech 방문 연구원

- 2010년 KAIST 신소재공학과 연구교수

( 2011년-2016년 한국재료연구원 선임연구원

( 2017년-현재 한국재료연구원 책임연구원

\section{•• 민유호}

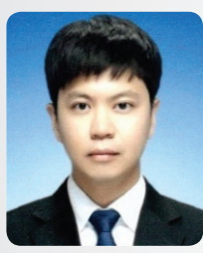

- 2003년-2015년 연세대학교 재료공학 학사. 석사, 박사

- 2015년-2017년 LG화학 기술연구원 책임

- 2017년-현재 한국재료연구원 선임연구원 